\section{O CONCEITO DE ANGÚSTIA E SUAS RELAÇÕES COM A LINGUAGEM}

\author{
The Anxiety Concept and its Relations with the Language \\ El Concepto de Angustia y sus Relaciones con la Lenguaje \\ Le Concept D'angoisse et ses Rapports avec Langage
}

Artigo Original

O objetivo deste trabalho é sustentar a hipótese de que o conceito da angústia, assim como os demais conceitos da economia psíquica, podem ser abordados segundo o axioma lacaniano do inconsciente estruturado como uma linguagem. Com este intuito, percorremos as duas teorias freudianas da angústia, a primeira como afeto transformado a partir do recalque, e a segunda, pertencente à segunda tópica, da angústia como sinal que aponta para o recalque, ou seja, como causa deste. Em seguida, propomos um cotejo entre o conceito de angústia e as descrições de transtorno de ansiedade presentes no DSM-IV-TR e na CID 10, com o objetivo de apontar para um resquício da utilização da terminologia freudiana nos manuais, apesar de sua proposta universalizante e estritamente descritiva, sem o uso de referências teóricas diretas. Nossa proposta, ao fazer este diálogo, indica que há mais divergências do que aproximações entre os apontamentos freudianos e tal modelo de nosografia, já que esta separa fenômeno e sujeito, sem considerar as causalidades e a possibilidade de produção subjetiva. Ao contrário deste apagamento do sujeito proposto pelos manuais, temos as conceituações lacanianas sobre angústia, sobretudo a partir do Seminário 10, como afeto que não engana e como constitutivo da estruturação subjetiva. Dentro desta perspectiva, destacamos alguns aspectos da abordagem da angústia na clínica psicanalítica, a partir dos conceitos de objeto a e do discurso do analista como norte para a atuação do psicanalista.

Palavras-chave: psicanálise; angústia; linguagem; afeto; clínica.

\begin{abstract}
This work aims to propose the hypothesis that the anxiety concept, as well as other concepts of psychic economy, can be approached according to the lacanian axiom of unconscious structured as a language. With this purpose, we traverse the two Freudian theories of anxiety, the first as affect turned from repression, and the second, belonging to the second topic model, the anxiety as a distress signal pointing to repression, or as its cause. Then, we highlight possible forthcomings and withdraws between the anxiety concept and descriptions of anguish disorder present in the DSM-IV-TR and CID-10, in order to point to a remnant of the use of Freudian terminology in those disorders manual, despite their universalizing and strictly descriptive proposal, without the use of direct theoretical references. Our goal during this dialogue, indicates that there are more differences than similarities between Freudian's remarks and such nosography model, since this one separates phenomenon and subject, without regard to causalities and the possibility of subjective production. Unlike this effacement of the subject marks proposed by the manuals, we have the Lacanian conjectures about anxiety concept, especially from the Seminary 10 as affect that does not deceive and as constitutive of subjective structure. Within this perspective, we highlight some aspects of the approach of trouble in psychoanalytic clinical practice, based on the object a concept and from the analyst discourse as a north to the role of the psychoanalyst.
\end{abstract}

Keywords: psychoanalysis; anxiety; language; affect; clinic.

\title{
Resumen
}

El objetivo de este ponencia es sostener la hipótesis de que el concepto de angustia, así

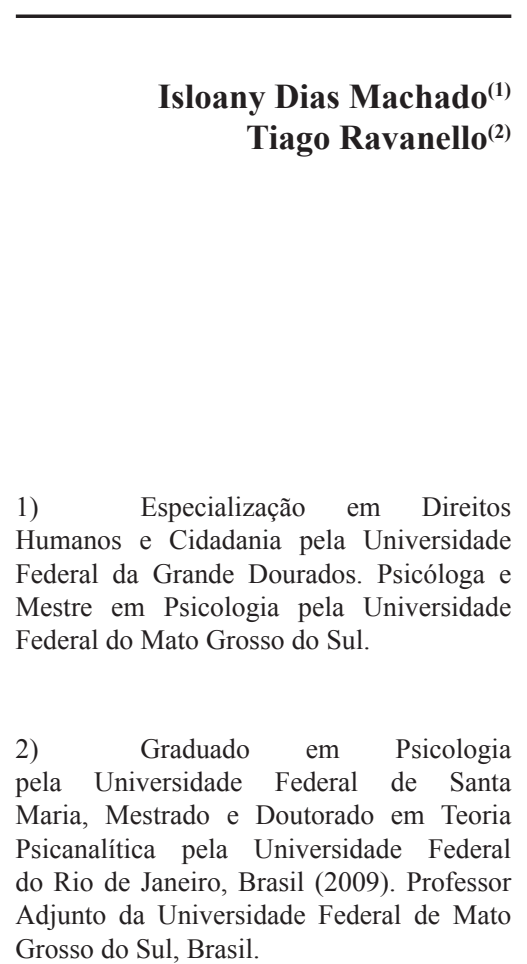

Recebido em: 19/04/2013

Revisado em: 19/06/2014

Aceito em: 19/11/2014 
como los demás conceptos de la economía psíquica, pueden ser abordados según el axioma lacaniano de "el inconsciente estructurado como un lenguaje". Con esta meta, recurrimos a las dos teorías freudianas de la angustia, la primera como afecto cambiado a partir del recalque, y la segunda, perteneciente a la segunda tópica, de la angustia como señal que apunta para el recalque, o sea, cómo la causa de este. Luego después, destacamos posibles aproximaciones y alejamientos del concepto de angustia con las descripciones del trastorno de ansiedad presentes en el DSM-IV-TR e en el CID 10, con el objetivo de apuntar para un resquicio de la utilización de la terminología freudiana en los manuales, aunque su propuesta sea universalisante y estrictamente descriptiva, sin el uso de referencias teóricas directas. Nuestra propuesta, al hacer este dialogo indica, que hay más divergencias que aproximaciones entre los conceptos freudianos y este modelo de nosografia, ya que este último hace la separación entre fenómeno y sujeto, sin considerar la causalidad y la posibilidad de producción subjetiva. Al contrario de este borrar del sujeto propuesto por los manuales, tenemos las concepciones lacanianas sobre la angustia, sobretodo a partir del seminario 10, como afecto que no engaña y como constitutivo de la estructuración subjetiva. Dentro de esta nueva perspectiva, destacamos algunos aspectos del abordaje de la angustia en la clínica psicoanalítica, a partir de los conceptos de objeto a y del discurso del psicoanalista como derrotero para la acción del psicoanalista.

Palabras clave: psicoanálisis; angustia; lenguaje; afecto; clínica.

\section{Résumé}

L'objectif de ce travail est de proposer l'hypothèse selon laquelle le concept d'angoisse, ainsi que d'autres concepts de l'économie psychique, peuvent être traités conformément à l'axiome de l'inconscient lacanien structuré comme un langage. À cette fin, nous parcourons les deux théories freudiennes de l'angoisse, la première comme affect modifié a partir du refoulement, et la seconde, appartenant au deuxième modèle topographique, de l'angoisse comme signal qui point au refoulement, ou comme la cause de celui. Puis, nous mettons en evidence les possibilités des raprochements et enloingments entre le concept d'angoisse et les descriptions de trouble d'angoisse présent au DSM-IV$T R$ et CID-10, au fin de indiquer vestiges de l'utilisation de la terminologie freudienne aux manuels diagnostiques, en dépit de leur proposition de carateristique universel et strictement descriptif, sans l'utilisation des références théoriques directes. Notre proposition en envisager ce dialogue indique qu'il ya plus de différences que de similarités entre les idées freudiennes et telle modèle nosographique, puisque cette dérnière met en disjonction le phénomène et le sujet, sans égard à la causalité et la possibilité de la production subjective. Contrairement à cet effacement du sujet proposé par les manuels, nous avons les concepts lacaniens d'angoisse, en particulier du Séminaire 10 comme affect qui ne déçoit pas et comme constitutive de la structuration subjective. Dans cette perspective, nous mettons en évidence certains aspects de l'approche des problèmes dans la pratique psychanalytique, basée sur les concepts de l'objet a et du discours de l'analyste comme au nord du rôle du psychanalyste.

Mots-clés: psychanalyse; angoisse; langage; affect; clinique.
A psicanálise tem como uma de suas implicações éticas voltar-se para os problemas decorrentes do malestar na cultura, com a finalidade de situar criticamente a pesquisa teórico-conceitual, bem como, implicar seu procedimento de pesquisa com a prática clínica e suas demandas. A angústia é considerada pela produção bibliográfica psicanalítica como um dos conceitos pilares deste campo. As razões pelas quais este conceito pode ser considerado de fundamental importância são diversas e, dentre elas, destacaremos algumas sem a pretensão de esgotar as possibilidades. O conceito de angústia esteve presente desde as origens dos estudos psicanalíticos, ainda que nem sempre o encontremos relacionado diretamente com as psicopatologias. Ao mesmo tempo, pode ser situado no cerne dos fenômenos psíquicos investigados por Freud e, muitas vezes, no aspecto do manejo clínico, pode servir de indício para as construções em análise, bem como ser tomado como um guia da interpretação, ao apontar para a verdade do sujeito.

Mesmo com toda esta importância que ocupa no campo da psicanálise, o estatuto conceitual da angústia não foi fechado, nem por Freud - que estabeleceu duas teorias da angústia -, nem por Lacan. Isto implica que, mesmo tendo pontos de convergência, existem contradições entre estas teorias. Freud, por exemplo, utiliza elementos de sua primeira teoria ao postular a segunda. Isto por si só não é problemático, já que está em processo de construção teórica, porém cada uma delas possui bases epistemológicas distintas e isso não pôde ser reconhecido por Freud naquele contexto científico e histórico. Nosso objetivo não é estabelecer qual a mais completa teoria da angústia, mas, sim, trabalhar as contradições dentro do campo psicanalítico, mais especificamente nas teorias de Freud e Lacan, bem como agrupar e elencar possibilidades de abordagens deste conceito cujo estatuto epistemológico não é o mesmo dentro da própria psicanálise. Neste aspecto, a angústia seria para Freud um guia na análise e, para Lacan, teria valor de índice do real. Assim, para ambos, teria um valor de ordenamento da ação.

A temática da angústia tem sido amplamente incluída na ordem das publicações no campo da psicologia e também no âmbito da psicopatologia, o que favorece as discussões epistemológicas de suas bases de construção. As pesquisas sobre o conceito de angústia apresentam-se a partir de diversos embasamentos teóricos e epistemológicos. Tal conceito tem sido trabalhado em suas conexões, como por exemplo, na aproximação entre a angústia e o desamparo (Andre, 2001; Costa \& Queiroz, 2012); angústia e síndrome do pânico(Lyra, 2008); angústia e pulsão de morte(Lourenço, 2012); angústia e desejo (Viola \& Voracaro, 2011); além de constituir-se como retomadas das teorias de Freud e Lacan (Campos, 2012; Castilho, 2012; Pisetta, 2012). Assim, o 
conceito de angústia pode ser tomado igualmente como fio condutor no entendimento de outras conceituações importantes, tais como os processos econômicos de forma geral, que possuem estatuto de difícil abordagem na medida em que aponta os impasses epistemológicos próprios ao campo psicanalítico.

Com toda a construção teórica estabelecida sobre o tema, é possível notar também a grande quantidade de casos clínicos cuja queixa reincide na questão da angústia. Há um número significativos de casos que chegam aos consultórios de psicólogos, psicanalistas e serviços psi de forma geral tendo já passado pelo crivo e/ou diagnosticados de acordo com os sistemas nosográficos modernos como "transtornos de ansiedade". Este eixo de diagnose abre o leque para outros termos cuja descrição fenomenológica se assemelhariam ao que Freud estabeleceu no quadro da neurose de angústia (1895/1996b). Desta maneira, os sinais descritos no DSM-IV-TR (American Psychiatric Association [APA], 2002) e componentes, por exemplo, dos ataques de pânico, ansiedade generalizada e agorafobia, ao delimitar a temática da intensidade como critério diagnóstico, supostamente se assemelhariam aos sinais da angústia, conforme já destacado por Freud, o que requer discussão e posicionamento. Diante desse debate contemporâneo, quais as contribuições concernentes à psicanálise? Faz-se necessário que a psicanálise se volte constantemente para esta temática com o intuito de contribuir para a discussão das novas formas de mal-estar nas subjetividades e os desafios impostos por elas à clínica psicanalítica contemporânea.

No primeiro item, retomaremos rapidamente alguns pontos da história do surgimento da psicanálise, bem como das duas teorias da angústia em Freud, com a finalidade de trazer uma pequena apresentação destas, já que e o processo de criação deles não se separa da história da psicanálise. Além disso, destacaremos algumas posições da psiquiatria moderna quanto à temática a partir dos textos do DSM-IV$T R$ (APA, 2002), e buscaremos estabelecer um cotejo entre esta e a posição freudiana. Já no segundo item, traremos alguns aspectos da teoria lacaniana sobre a angústia, sua importância na clínica, visando uma releitura do conceito de angústia a partir do axioma do inconsciente estruturado como uma linguagem.

\section{O Conceito de Angústia na Teoria Freudiana: Duas Abordagens}

O conceito de angústia dentro do campo psicanalítico, desde Freud, está inserido numa discussão mais ampla a respeito do tema do afeto e, por consequência, dos processos econômicos. Também para Lacan, a angústia é um afeto. Desta forma, tanto para um autor como para outro, ela aproxima-se dos conceitos da economia psíquica. Veremos a seguir que, por exemplo, em uma das elaborações teóricas propostas por Freud sobre o conceito de angústia, esta seria uma das transformações sofridas pela quantidade de afeto após o processo de recalcamento. Como neste primeiro item faremos um delineamento das teorizações freudianas sobre a angústia, faz-se necessário iniciarmos pela entrada do conceito de quantidade de afeto no processo de elaboração teórica em Freud. Este termo foi utilizado pelo autor ao abordar inicialmente os mecanismos pelos quais ocorriam as paralisias histéricas (1893/1996). Trata-se de um termo importante da economia psíquica que será retomado nas teorizações freudianas sobre a pulsão, a representação, o recalque, entre outros, ou seja, é um termo que serve para dar consistência ao enfoque econômico em função do peso epistemológico implicado na noção de quantidade enquanto recurso explicativo próprio às ciências da natureza. Para dimensionarmos a importância deste conceito de quantidade de afeto, temos, em uma das abordagens freudianas da angústia, o surgimento desta a partir da transformação da quantidade de afeto durante o processo de recalque. Em outras palavras, angústia seria quantidade de afeto transformado, conforme o texto de Freud sobre o Recalque (1915/1996). Ainda em Freud, temos a possibilidade de conceituar a angústia como transformação a partir do excesso de libido acumulada, conforme o Rascunho E (1894/1996). Em contraposição, de acordo com Freud em seu texto sobre Inibições, Sintomas e Angústia (1926/1996), na segunda tópica, temos ainda a angústia como aquilo que apontaria para o recalque, para que o aparelho pudesse se proteger - recalcando - conteúdos traumáticos atuais que tivessem relação com as cenas iniciais traumáticas, em nome da preservação do aparelho psíquico. Desta forma, diante de possibilidades que ora convergem, ora divergem, faz-se necessário delinear algumas considerações históricas para acompanhar o processo de construção teórica freudiana do conceito de angústia, a partir dos pilares conceituais e é neste viés que construímos o primeiro item deste trabalho. Devido à importância do conceito de quantidade de afeto, e por ser este inicialmente encontrado nas construções teóricas sobre a histeria, faremos uma retomada desta para falar sobre tal conceito tão importante para as considerações sobre a angústia.

Os escritos psicanalíticos são iniciados por Freud a partir do estudo das manifestações histéricas, algo que vinha sendo estudado por Charcot no hospital parisiense Salpetrière, na França. A proposta de Charcot era conferir à histeria o status de uma entidade clínica com leis próprias, e Freud, em seu período de estágio em Paris, soube destacar os elementos necessários para uma nova escuta. Seus estudos, neste período, juntamente com Charcot, buscavam uma correspondência orgânica para as lesões e manifestações histéricas. Durante este período, Freud publicou um texto, 
em francês, intitulado Algumas considerações para um estudo comparativo das paralisias motoras orgânicas e histéricas (1893/1996). Neste texto, ele faz uma explanação dos dois tipos de paralisias: de um lado, as paralisias motoras de base orgânica, de outro, as paralisias motoras de estrutura histérica. Após descrever o funcionamento das paralisias motoras orgânicas, Freud afirma que a histeria possui uma capacidade de "simular as mais diferentes doenças nervosas orgânicas" e que "as paralisias histéricas somente compartilham as características das paralisias orgânicas em representação" (p. 205). Nesta citação, quando Freud afirma que a histeria está ligada a uma capacidade de "simular" uma doença orgânica, não é no sentido de considerar as histéricas como farsantes, já que até aquele momento da construção científica, o sofrimento delas não era tido como real. O que Freud traz, justamente ao contrário, é a possibilidade de compreender o fenômeno da histeria como um objeto de estudo, em função da busca por legitimidade de suas bases psicológicas tal como exposto na citação a seguir:

[...] a lesão nas paralisias histéricas deve ser completamente independente da anatomia do sistema nervoso, pois, nas suas paralisias ou em outras manifestações, a histeria se comporta como se a anatomia não existisse, ou como se não tivesse conhecimento desta [...]. A histeria ignora a distribuição dos nervos. [...] Ela toma os órgãos pelo sentido comum, popular, dos nomes que eles têm: a perna é a perna até sua inserção no quadril, o braço é o membro superior tal como aparece visível sob a roupa. [...] Portanto, na paralisia histérica, a lesão será uma modificação da concepção, da ideia de braço, por exemplo. (Freud, 1893/1996, pp. 212-213)

Com estas contribuições, Freud propõe uma nova abordagem a partir do conceito de representação, presente desde o texto sobre A Interpretação das Afasias (1891/2003). Com este conceito o autor traz os primeiros indícios da proposta de um aparelho psíquico enquanto aparelho de linguagem, o que foi retomado posteriormente por Lacan a partir de sua abertura para temas vinculados às teorias da linguagem e ao estruturalismo francês. Freud, ao questionar o que seria capaz de produzir a paralisia histérica, inclui o conceito de "quantidade de afeto":

Se, numa associação, a concepção do braço está envolvida com uma grande quantidade de afeto, essa concepção será inacessível ao livre jogo das outras associações. O braço estará paralisado em proporção com a persistência dessa quantidade de afeto ou com a diminuição através de meios psíquicos apropriados. (Freud, 1893/1996, p. 214)
A teoria freudiana abre como perspectiva, neste momento, a possibilidade de pensar que o motivo da paralisia do braço seria quantidade de afeto investida na ideia de braço. Desta forma, as paralisias seriam justificadas por um determinado tipo de relação entre quantidade de afeto e ideia, ao invés de uma lesão localizada no material orgânico. Neste artigo de 1893, Freud trabalha o conceito de quota de afeto e, posteriormente, no escrito metapsicológico de 1915 sobre o recalque, define o conceito de quota de afeto como um "representante da pulsão". Nos dois momentos ele está buscando construir uma resposta às suas hipóteses sobre a economia psíquica a partir de conceitos que envolvem energia psíquica. É importante destacar que Freud articula então ideia, afeto e pulsão, de forma que os dois primeiros sejam representantes da última. Deste modo, a pulsão só existiria quando fosse presentificada, no inconsciente, por seus representantes: afetivo e ideativo.

Dentro da primeira teoria freudiana da angústia é possível destacar duas abordagens deste conceito. Uma delas está presente no Rascunho E (1894/1996), no qual Freud afirmou que a angústia não estaria contida no que é acumulado, mas que a situação se definiria dizendose que esta surgiria por transformação a partir da tensão sexual acumulada. A outra posição está presente no texto metapsicológico sobre o Recalque (1915/1996), no qual o autor propõe que o aspecto quantitativo do representante pulsional tem três destinos possíveis: "ou a pulsão é inteiramente suprimida, de modo que não se encontra qualquer vestígio dela, ou aparece como um afeto que de uma maneira ou de outra é qualitativamente colorido, ou transformado em angústia" (Freud, 1915/1996, p. 158). Desta maneira, a angústia como um afeto transformado, seria um dos possíveis destinos do aspecto quantitativo da pulsão. Portanto, na primeira teoria freudiana, temos a angústia como afeto transformado a partir do recalque, ou ainda como transformação a partir da tensão sexual acumulada. À primeira vista, trata-se de uma aparente contradição, mas em ambos os casos, estamos diante de um processo automático de descarga de excitação psíquica. Desta forma, apesar do tom contraditório na colocação do argumento, defendemos a leitura de que a descrição freudiana presente no texto sobre o recalque veio complementar as teorizações do rascunho E. Esta possibilidade se justifica na medida em que, epistemologicamente, ambas tratam de formas automáticas de descarga energética. Tais são os levantamentos pertinentes à primeira teoria da angústia em Freud, em seguida vejamos as questões relativas à segunda teoria.

A criação da segunda teoria da angústia fica mais clara no texto Inibições, "Sintomas e Angústia" (1926/1996), e acompanha a construção da segunda tópica freudiana, mais especificamente a partir das teorizações sobre o ego. 
Segundo o comentário do editor inglês: "Freud desiste da teoria que sustentara por tanto tempo. Ele não considerava mais a angústia como libido transformada, mas como uma reação sobre um modelo específico a situações de perigo" (Freud, 1926/1996, p. 83). A visão adotada por Strachey, de que Freud teria abandonado completamente a primeira teoria da angústia em detrimento da segunda, não é consensual. Outra possibilidade é vislumbrada por Vieira, pois, segundo ele, contrariamente ao que pode ter parecido naquele momento em que Freud escreve que já não pode mais acreditar na elaboração anterior:

A passagem da primeira à segunda teoria da angústia em Freud provocou um vasto debate entre os pós-freudianos, assim como numerosas interpretações divergentes do texto de Freud com seus consequentes impasses. Ao contrário do que as palavras de Freud poderiam nos levar a crer, uma teoria não vem corrigir a outra. A teoria delimitada nos textos metapsicológicos de 1915 não é simplesmente rejeitada em proveito de ISA [Inibição, Sintomas e Angústia], como se esta fosse uma nova versão do mesmo fenômeno, uma explicação mais conclusiva e verdadeira. Também não se trata da coexistência de duas teorias incompatíveis, pois sabemos que são claramente interligadas, pondo em jogo conceitos, muitas vezes idênticos. (Vieira, 2001, p. 65)

Principalmente após seus escritos no texto A Interpretação dos Sonhos (1900), evidencia-se na teoria freudiana, a importância da linguagem, das palavras na constituição do aparelho psíquico. A leitura empreendida posteriormente, a partir do contexto cultural e intelectual da época, o zeitgeist, possibilitou a Lacan estabelecer uma ligação da psicanálise com as teorias da linguagem de uma forma sistematizada.

No texto Inibições, Freud afirma que o ego é a sede real da angústia e propõe outra abordagem, diferente do ponto de vista anterior de que a energia catexial do impulso recalcado seria automaticamente transformada em angústia. Na segunda teoria freudiana, de acordo com Dunker (2006), "Freud inverte os termos da relação entre recalque e angústia. Agora, a angústia não é o efeito do fracasso do recalcamento, [...]; agora, a angústia é causa do recalcamento" (p. 308). Para Freud, a angústia, portanto, "não é criada novamente no recalque; é reproduzida como um estado afetivo de conformidade com uma imagem mnêmica já existente" (1926/1996, pp. 96-97). Então, uma posição metapsicológica desta segunda abordagem do conceito de angústia afirma que esta, assim como os demais estados afetivos, se presentifica no aparelho psíquico no momento em que se estabelece uma relação com experiências traumáticas do início da vida e, diante de situações que possam ter ligação com as cenas iniciais. Tais afetos seriam desencadeados ou, em termos freudianos, revividos por meio da repetição e, portanto, teriam uma função dentro do aparelho psíquico. Segundo Vieira,

[...] É somente fazendo entrar em jogo, no exame das formações do inconsciente, o método linguísticopsicanalítico de Freud em toda a sua originalidade, que podemos vislumbrar novas bases conceituais, fora do enquadre cartesiano. Em termos mais clínicos, trata-se da entrada do registro da pulsão de morte na consideração psicanalítica. (2001, p. 49)

Nesta citação, o autor abre como possibilidade compreender de que maneira a teoria freudiana, ao propor originalmente o método "linguístico-psicanalítico", pode ser entendida por um viés que seja pautado na linguagem. Freud, a partir do que ficou conhecido como a virada teórica da primeira à segunda tópica, na década de 1920, aposta no conceito de compulsão à repetição, que seria uma maneira de reviver estas cenas iniciais. Não se trata de escolher uma teoria em detrimento da outra, mas sim, fazer possíveis relações entre ambas. Faz-se necessário destacar que na teoria freudiana temos bases epistemológicas diferentes, isto implica que as operações clínicas que são construídas a partir destas bases também divergem.

\section{A Angústia e os Sistemas Nosográficos}

Outra possibilidade levantada neste trabalho é a de buscar definições diferenciais do conceito de angústia daquelas próprias ao campo psicanalítico estabelecido pelas abordagens de Freud e Lacan. A partir disso, pretendemos fazer o contraponto destas com a proposta atual da classificação de transtornos mentais segundo o DSM-IVTR, no que diz respeito à concepção de ansiedade, como na CID-10, considerando que nesta última, os transtornos psíquicos são englobados no campo dos transtornos orgânicos. Pretendemos, com este contraponto, promover uma discussão entre os conceitos e seus referenciais teóricos, ou seja, do que a psicanálise chama de angústia e o que os manuais classificam como ansiedade, quais as questões subjacentes à discussão no que tange aos seus aspectos epistemológicos. Nosso interesse com o encaminhamento deste embate teórico entre a concepção freudiana de angústia e o construto de ansiedade presente nos manuais é apontar para uma apropriação terminológica distante, porém desvirtuada. Dito de outra forma, superficialmente a descrição da ansiedade nos manuais possui apropriações diretas de constructos freudianos referentes à primeira teoria da angústia. Porém, faz-se necessário ressaltar que a teoria freudiana leva em consideração as questões causais 
e contextuais, enquanto os manuais propõem categorias baseadas em dados empíricos com possibilidade de generalização dos resultados (APA, 2002, pp. 22-23). Nesse caso, a apropriação do discurso freudiano é feita da parte dos manuais não sem antes extirpar elementos fundamentais em sua caraterização epistemológica.

Uma das principais características dos manuais de classificação de doenças e transtornos, tal como o DSM-IVTR é a de buscar apoio e fundamentação em uma "ampla base empírica" (APA, 2002, p. 21). Além disso, afirmam ter sido feita uma sistemática revisão bibliográfica com a finalidade de obter informações "abrangentes e isentas, a fim de garantir que o texto refletisse a melhor bibliografia disponível" (p. 24). Tal posicionamento permitiu ao campo psicanalítico realizar uma leitura de a-teoricidade deste manual, já que a ênfase é dada aos aspectos empíricos, e não epistemológicos, para subsidiar a categorialização de entidades fenomenológicas universais, pois, apesar de ressaltarem que os resultados obtidos foram frutos de uma sistemática revisão bibliográfica, as fontes são suprimidas. Segundo Dunker e Neto, "o DSM tem como objetivo constituir-se num sistema de classificação sobre dados diretamente observáveis, sem recorrer a sistemas teóricos" (2011, p. 619). Deste modo, nossa hipótese é a de que a citada revisão bibliográfica possa ser lida como uma espécie de processo de depuração da teoria fundamentada num modelo epistemológico realista. Segundo este modelo, o caráter de verdade das assertivas seria extraído ou em função da sua aproximação com a observação, ou, pela recorrência e repetição dos discursos nas diferentes teorias. A crítica que a psicanálise endereça a tal modelo, sobretudo a partir de Freud (1914/1996), seria a de que a teoria se impõe sobre a observação, revelando a cada passo uma estrutura de sujeito da ciência e de contextos discursivos da comunidade científica. No modelo realista, o espaço do sujeito e seu contexto acaba sendo suprimido em função de ideais de objetividade e universalidade. Ao não apontar as fontes da pesquisa, é possível que estejam falando de muitos lugares teóricos - e, ao mesmo tempo, de nenhum lugar - e isto se torna problemático na medida em que aponta, novamente, para o estatuto realista da teoria.

Assim, apesar de ser possível estabelecer semelhanças terminológicas entre a teoria freudiana e os manuais, a partir do posicionamento empírico focado na descrição caracteriológica, houve um empobrecimento da causalidade. Os diagnósticos realizados de acordo com estes manuais partem do fenômeno, e este seria universal, independente dos fatores culturais e históricos em que ocorreriam. Retomamos isto para dizer que os manuais de saúde mental, tais como o DSM, têm sido revisados e a cada edição os transtornos psíquicos são descritos a partir do fenômeno, sem contextualização social e teórica, indicando para a ruptura cada vez maior entre a psicopatologia psiquiátrica e as teorias que a sustentam. Como definir critérios de sucesso na abordagem de um fenômeno que não passe pelo crivo da teoria? Dunker e Neto (2011) afirmam que este sistema empírico serve às exigências do pragmatismo e este compromisso traz como consequência o enfraquecimento da ciência enquanto base epistemológica.

Segundo Leite (2011), quando partimos somente do fenômeno da doença para estabelecer diagnósticos, notamos o abandono das construções teóricas sofrido no campo da medicina. A autora se refere às bases da psiquiatria clássica, que foram gradativamente sendo abdicadas na medida em que os manuais passaram a ser baseados supostamente num fenômeno que não comporta teoria. Ainda de acordo com esta autora, não é coincidência que os criadores dessa nova nosografia possam ser tomados no campo psicanalítico como a-teóricos, considerando a classificação das doenças como fruto de um contato direto com o real da própria doença, ou seja, com o fenômeno em si. A partir disso, segundo a crítica feita pela autora, presume-se uma leitura dos fenômenos, de sua compreensão, sem a mediação simbólica propiciada pelos constructos teóricos (Leite, 2011).

Conforme afirmamos anteriormente, bases importantes para a conceptualização do termo "ansiedade" nos manuais foram instituídas a partir de apropriações da teoria freudiana da angústia (sobretudo a primeira), no entanto, sem a devida discussão a respeito da estrutura epistemológica que a sustenta. Vejamos como o termo "ansiedade" se apresenta nos manuais através de sua localização em diferentes transtornos: no DSM-IV-TR (APA, 2002), temos o item "Ansiedade Generalizada" e "Ansiedade", este segundo é subdividido em outros, tais como Ataque de Pânico, Transtorno de Pânico Sem ou com Agorafobia, Fobia Social, Transtorno Obsessivo-Compulsivo, Transtorno de Estresse Pós-Traumático, Transtorno de Ansiedade Generalizada, etc. Notamos que nesta classificação temos a "ansiedade generalizada" como um subitem da "ansiedade". Conforme o que foi anteriormente citado no texto sobre a possível relação entre "angústia" e "ansiedade" na edição standard brasileira das obras freudianas, duas questões são levantadas para compreender esta classificação do manual: a diferença estaria na variação de intensidade entre dois fenômenos de mesma estrutura ou, por outro lado, na mudança de abrangência entre fenômenos semelhantes, porém, estruturada com elementos somados de diferentes ordens? Nesse segundo caso, a angústia comportaria a ansiedade dentro de um rol de hierarquia (inexistente na teoria freudiana) dos sintomas, na medida em que a segunda seria a primeira somada às manifestações somáticas. Vejamos a especificidade da "ansiedade generalizada" de acordo com as características diagnósticas listadas no DSM: 
Uma ansiedade ou preocupação excessiva (expectativa apreensiva), ocorrendo na maioria dos dias por um período de pelo menos 6 meses, acerca de diversos eventos ou atividades. [...] O foco da ansiedade e preocupação não está confinado a aspectos de um outro transtorno do Eixo I, como ter um Ataque de Pânico (no Transtorno de Pânico), sentir embaraço em público (na Fobia Social), ser contaminado (no Transtorno Obsessivo-Compulsivo), [...]. A intensidade, duração ou frequência da ansiedade ou preocupação são claramente desproporcionais à real probabilidade ou impacto do evento temido. (APA, 2002, p. 457, grifos nossos)

\section{E na CID-10:}

Ansiedade generalizada e persistente que não ocorre exclusivamente nem mesmo de modo preferencial numa situação determinada (a ansiedade é "flutuante"). Os sintomas essenciais são variáveis, mas compreendem nervosismo persistente, tremores, tensão muscular, transpiração, sensação de vazio na cabeça, palpitações, tonturas e desconforto epigástrico. Medos de que o paciente ou um de seus próximos irá brevemente ficar doente ou sofrer um acidente são frequentemente expressos. Estado ansioso, Neurose ansiosa, Reação de angústia. (World Health Organizatio [WHO], 1993, p. 138 , grifos nossos)

Segundo o DSM (APA, 2002), este transtorno se diferencia dos transtornos de "ansiedade" por não conter o risco de um ataque de pânico, por exemplo, mas sua intensidade, duração ou frequência são desproporcionais à possibilidade de ocorrência do evento temido. As questões a serem levantadas referem-se à forma pela qual se avalia, por exemplo, a intensidade ou a probabilidade de ocorrência de um evento: qual o ponto de vista adotado para fazer tal classificação? Na CID-10 (WHO, 1993), trata-se de algo "persistente que não ocorre exclusivamente nem mesmo de modo preferencial numa situação determinada". Atentemo-nos para o detalhe ao final da citação em que chama a ansiedade generalizada de "reação de angústia", neste caso, para a CID-10 ansiedade e angústia seriam sinônimos? A "ansiedade generalizada" seria uma preocupação desproporcional, mas não extrema a ponto de desencadear um ataque paralisante, seria menos intensa do que um ataque de pânico. Uma vez mais, questionamos os critérios adotados para se definir que uma preocupação seja desproporcional ou que um evento seja mais ou menos intenso do que outro. Tanto numa situação quanto na outra, o que deveria ser discutido é, em primeiro lugar, qual a concepção de intensidade que permitiria uma distinção.

Os termos destacados como "expectativa apreensiva" e "flutuante", em ambas as citações anteriores, são familiares à terminologia freudiana em sua conferência sobre a angústia, apresentada em 1917. No primeiro caso, o termo é semelhante: "apreensão generalizada", e no segundo, é exatamente o mesmo: livremente "flutuante". Neste texto, Freud fala de dois tipos de angústia, a realística e a neurótica. A realística seria "uma reação à percepção de um perigo externo [...], de um dano que é esperado e previsto. Está relacionada ao reflexo de fuga [...]" (1917/1996, p. 395). Os motivos que disparariam esta angústia dependeriam do saber do indivíduo sobre os riscos que corre frente a um fator externo. Poderíamos dizer que se relaciona ao medo de algo real, mas este real varia conforme a experiência de cada um.

Na teoria freudiana, em oposição à angústia realística, temos a angústia neurótica. Freud classifica-a segundo três perspectivas. A primeira seria a "angústia livremente flutuante" que, segundo ele, se trata de uma "apreensão generalizada pronta para se ligar a alguma ideia que seja de algum modo apropriada a este fim, [e] que influencia o julgamento [...]" (Freud, 1917/1996, p. 399). Neste excerto do texto freudiano, temos um ponto de convergência com aquilo que o DSM (APA, 2002) chama de "expectativa apreensiva" ou "preocupação excessiva acerca de diversos eventos ou atividades" (p. 457), na sua classificação de “ansiedade generalizada". Mas Freud não limita a questão temporal como um critério diagnóstico, assim como faz o DSM (APA, 2002): “ocorrendo na maioria dos dias por um período de pelo menos 6 meses.” (p. 457).

Retomamos a angústia neurótica para citar a segunda possibilidade vislumbrada por Freud, qual seja, a de uma angústia psiquicamente ligada, isto é, "vinculada a determinados objetos e situações". Para o autor, tratase da "angústia das 'fobias', extremamente multiformes [...]" (Freud, 1917/1996, p. 399). O autor afirma serem incontáveis os objetos que podem ser elencados como fóbicos, e destaca que as fobias dos neuróticos chamam a atenção pela intensidade, pois a angústia presente é "efetivamente avassaladora" (1917/1996, p. 400). Diz ainda que o conteúdo não chama mais à atenção do que o aspecto de intensidade, já que o conteúdo e suas relações com as motivações psíquicas, somente podem ser obtidas caso a caso. Além disso, para Freud, nas fobias, um perigo externo insignificante é introduzido para representar as exigências da libido (1917/1996). No DSM (APA, 2002), temos como item de classificação a Fobia Específica, que "caracterizase por ansiedade clinicamente significativa provocada pela exposição a um objeto ou situação específicos e temidos, frequentemente levando ao comportamento de esquiva" (p. 431). Este é um ponto de aproximação com a teoria freudiana, no que tange ao conceito de angústia realística, mas afasta-se da definição de fobia. Para Freud, na fobia o objeto temido está no lugar de outro, como representante 
das exigências da libido e não como um objeto qualquer.

Voltemos aos três tipos de angústia neurótica, descritos por Freud. O terceiro tipo de angústia neurótica seria aquele presente nas neuroses histéricas ou outras neuroses graves em que, ou ela acompanha os sintomas, ou surge independentemente como ataque. Para o autor, no caso da histeria, "quando temos diante de nós um estado de angústia histérica, seu correspondente inconsciente pode ser um impulso de características semelhantes - angústia, vergonha, embaraço" (p. 404). No caso de outros tipos de neurose, se tentarmos impedir, por exemplo, os atos obsessivos de um paciente, aparentemente isentos de angústia, este é acometido da "mais terrível angústia a submeter-se à compulsão" (1917/1996, p. 404). Segundo Freud, num caso como este, a angústia estava "encoberta pelo ato obsessivo" e este "só foi executado com o fito de evitá[-la]" (p. 404). Nesta perspectiva, a formação dos sintomas, tanto os da histeria como os da neurose obsessiva, são para evitar a angústia, que seria inevitável de outra maneira.

Outro exemplo semelhante de contraponto e de apropriação da superfície do discurso freudiano sem a devida discussão e exposição de suas bases pode ser delimitado na estrutura denominada em psicanálise como neurose obsessiva, e que no DSM (APA, 2002) descrevese como Transtorno Obsessivo-Compulsivo, que pode ser caracterizado por "obsessões (que causam acentuada ansiedade ou sofrimento) e/ou compulsões (que servem para neutralizar a ansiedade)" (p. 419). Desta forma, para o DSM, um aspecto causaria e outro neutralizaria a angústia. Nesta comparação, há divergência com a teoria freudiana, já que os atos obsessivos não são a causa da angústia, mas servem para evitá-la.

O texto utilizado como referência para a discussão realizada, conforme anunciamos anteriormente, foi pautada na Conferência de Freud sobre a angústia, proferida em 1917. Deste modo, é importante destacar que pertence às construções de sua primeira teoria da angústia. À diferenciação feita por Freud entre angústia realística e neurótica, cabe uma ressalva. Ao considerarmos a possibilidade da existência de uma angústia ligada diretamente à função de autopreservação, como foi conceituada a realística, perdemos o fundamento também freudiano de que a realidade é psíquica, ou seja, tem sua condição autônoma de existência. Assim, a definição de angústia realística aponta para um resquício de naturalismo na teoria freudiana. Isto é problemático se for tomado em uma leitura que reduza a teoria freudiana a um enfoque biologizante, radicalmente divergente daquele aqui adotado e que propõe a releitura dos construtos a partir do campo da linguagem, apoiado na leitura lacaniana.

De acordo com os elementos por ora citados, cabe reafirmar que tivemos como objetivo aproximar o conceito freudiano de angústia com os manuais descritivos para apontar que, apesar das aparentes semelhanças terminológicas entre ambos, houve um apagamento das bases epistemológicas e causais que são fundamentais na teoria psicanalítica, e que sequer são citadas nos manuais de classificação de doenças mentais. Deste modo, há uma divergência radical no modus operandi do diagnóstico psicanalítico, que é estrutural, e o baseado nos manuais, apoiado no fenômeno separado de qualquer tipo de causalidade psíquica. Segundo Dunker e Neto (2011), todo sintoma exprimiria uma produção subjetiva e, apesar de sua interface prejudicial, haveria também a expressão de uma possibilidade de solução criada pelo próprio sujeito. Assim, a crítica feita pelo campo psicanalítico, corroborada por nós, ao modelo nosográfico proposto nos manuais refere-se ao apagamento do sujeito, na medida em que o sintoma é tomado enquanto fenômeno e não como produção subjetiva.

Em oposição ao recorte feito neste trabalho a respeito da posição dos sistemas nosográficos modernos, representados principalmente pelo DSM e a CID, temos a conceituação da angústia a partir da teoria lacaniana, descrita principalmente no Seminário 10 (1962-63). Um dos interesses deste artigo são as contribuições lacanianas sobre este conceito, a partir da releitura das teorias de Freud, com a finalidade de pensarmos em suas relações com a linguagem, tendo como base o axioma do inconsciente estruturado como uma linguagem. Abordaremos este percurso ora indicado no item seguinte.

\section{O Conceito de Angústia na Teoria Lacaniana}

De acordo com a maneira pela qual encaminhamos acima a leitura do texto freudiano, temos o estatuto conceitual da angústia na teoria psicanalítica apresentando duas possibilidades. A primeira considera a angústia como um afeto automaticamente transformado, neste caso ela seria um dos possíveis destinos do afeto, após o recalcamento, enquanto representante pulsional no psiquismo. Na segunda teoria, a angústia, ao invés de ser efeito do fracasso do recalque, seria, pelo contrário, sua causa. Teria, assim, a função de avisar o ego sobre os perigos - do mundo externo, mas principalmente do interno - que pudessem ameaçar o aparelho psíquico. Ambas as teorias foram propostas por Freud em períodos diferenciados de sua construção teórica e possuem bases epistemológicas diferentes. No processo de construção da teoria freudiana, foi preciso estar em constante revisão conceitual e, se Freud pesquisava inicialmente em seu trabalho uma correspondência orgânica para o aparelho psíquico, conforme uma base inicial naturalista, segundo nossa leitura, o delineamento da teoria psicanalítica deve ser pensado justamente na ruptura gradual com as bases naturalistas inicialmente presentes no texto freudiano. 
Lacan, em seu percurso teórico, critica o caminho tomado pela psicanálise com os pós-freudianos, tais como Melanie Klein e Anna Freud, pois estes autores criaram uma teoria - psicologia do ego - que dá ênfase a um ego forte, contrariamente ao que havia sido proposto por Freud sobre o ego não ser senhor em sua própria morada. Lacan retoma a teoria freudiana e afirma que a teoria estaria tomando rumos diferentes daquilo proposto por Freud sobre a importância maior da decifração do inconsciente a partir da fala do paciente. Em seu texto Função e Campo da Fala e da Linguagem, Lacan aponta que, ao analisarmos o pósfreudismo, podemos notar uma "aversão do interesse pelas funções da fala e pelo campo da linguagem" (1953/1998, p. 243). Segundo o autor, isto teria sido consequência de três aspectos: 1) a partir da psicanálise infantil e a proposta de estudar as estruturações pré-verbais, haveria sido dado um excesso de importância para aquilo que chamou de função imaginária em detrimento da função simbólica; 2) a psicanálise teria desembocado em uma "fenomenologia existencial, ou até num ativismo movido pela caridade" (p. 244); 3) a questão da ênfase na interpretação a partir da contratransferência, bem como da formação do psicanalista que, ao interpretar a partir daquilo que o paciente teria the despertado, estaria na relação analítica como sujeito e não como objeto. Segundo Lacan, "esses três problemas têm um traço comum [...]. trata-se da tentação que se apresenta ao analista de abandonar o fundamento da fala" (p. 244).

Esta crítica levantada por Lacan, referente aos problemas em que a psicanálise se encontrava, leva-o a afirmar que, diante de tal situação, era necessário o retorno ao estudo da teoria freudiana, "no qual o psicanalista deveria tornarse mestre/senhor, das funções da fala" (p. 245). Seguindo a perspectiva freudiana de constante reelaboração teórica, Lacan retoma os pressupostos freudianos, que não haviam rompido definitivamente com as ciências da natureza com o intuito de reformulá-los a partir de sua releitura embasada no axioma do inconsciente estruturado como linguagem. Faz, assim, uma espécie de convite à releitura de Freud e este convite é estruturante do campo da psicanálise lacaniana.

Os conceitos da teoria psicanalítica freudiana tais como a estrutura psicótica e seu manejo clínico, as relações de objeto, as formações do inconsciente, o corpo, dentre outros, foram revisados por Lacan em seus seminários anuais. Também propôs a revisão dos conceitos da economia psíquica (pulsão, afeto, libido, investimento, catexia, angústia), historicamente ligados a uma concepção energética do aparelho psíquico. Lacan realizou grande parte das revisões que propôs, a partir das teorias da linguagem, mas o trabalho não foi concluído, nem se esperava que fosse, já que a pesquisa em ciência deve estar em constante reestruturação.

A angústia é, conforme dito anteriormente, um dos conceitos da economia psíquica freudiana, pois está no campo dos afetos, tanto na primeira quanto na segunda tópica. Estando no campo dos afetos, faz-se necessário destacar rapidamente alguns aspectos de como este conceito foi tratado na teoria lacaniana, para, então, nos posicionar a respeito do conceito de angústia.

O conceito de afeto tem especial importância no decorrer da elaboração teórica, pois permeou diversos aspectos da construção psicanalítica em Freud e, como vimos a respeito da primeira teoria da angústia, os conceitos de afeto e de quantidade de afeto estão diretamente implicados na concepção freudiana de economia psíquica . Entretanto, apesar da proposta de reelaboração da teoria freudiana, o conceito de afeto está disperso na teoria lacaniana, ou seja, não está sistematizado em algum texto ou seminário específico, com exceção de passagens sobre o tema. Dentre os textos que abordam a temática, daremos ênfase a O Seminário: Livro $10(1962-1963 / 2005)$ e ao texto Televisão (1973/2003). Por não ter elaborado um estudo sistemático sobre o tema, ainda que tenha feito a retomada deste conceito em textos esparsos, Lacan sofreu críticas de que o teria "amputado" de sua teoria. Tal crítica teria sido feita, mais especificamente, por Green (1982), um dos interlocutores de Lacan.

Diante desta crítica, Lacan propõe que "o que se deve pesar é se minha ideia de que o inconsciente é estruturado como uma linguagem permite verificar mais seriamente o afeto - do que a ideia expressada de que ele é um tumulto em que se produz uma disposição melhor." (1973/2003, pp. 522-523). Assim, Lacan sustenta que é a partir do axioma do inconsciente estruturado como uma linguagem que deve ser feita a retomada da teoria psicanalítica. Portanto, retomar o afeto dentro deste estatuto é uma exigência epistemológica. Embora não tenhamos uma versão final sobre a teoria dos afetos, o que se pode supor é que o autor tomou como atitude, renunciar à ordem material/substancial que imperava até então com as concepções do ponto de vista econômico da psicanálise, em prol de uma pesquisa do campo da linguagem.

Com a renúncia lacaniana a uma teoria substancialista do afeto, podemos supor que ele se coloca, frente aos processos econômicos da teoria freudiana, disposto a retomá-los segundo operações discursivas, em conformidade com seu axioma do inconsciente estruturado como uma linguagem. Se há algum tipo de materialidade na psicanálise lacaniana, ela não está relacionada a substâncias e/ou energias corporais, mas sim à materialidade presente no que a palavra afeta o corpo - que não coincide ponto a ponto com o biológico. Lacan (1975/1985) utiliza o neologismo moterialismo numa condensação de mot, que significa "palavra" em francês, ao termo materialismo para dizer que a materialidade da psicanálise está nas palavras, 
no discurso, e que é isso que afeta o corpo. Para Lacan, o que afeta os corpo são os significantes de alíngua que, segundo Quinet (2009), fazendo referência a Lacan, é aquilo que o sujeito recebe como chuva de significantes resultantes da língua materna, depositando-se para ele como material sonoro repleto de sentidos e equívocos.

Levando em consideração o objetivo de delinear os elementos para a discussão dos processos econômicos pela via discursiva em Lacan, retornaremos ao conceito de angústia com a proposta de retomá-lo também segundo o axioma do inconsciente estruturado como uma linguagem. No Seminário 10, Lacan retoma uma posição já anteriormente delimitada na qual ele propõe um tema central na teoria da angústia, dizendo ser ela um afeto que não engana. Sendo um afeto, tal como é postulado também por Freud, e segundo a possibilidade de leitura da teoria lacaniana que sustentamos, de renunciar uma conceituação substancialista, nossa proposta é abordar a angústia também como uma operação discursiva. Ao considerar a concepção da angústia como afeto que não engana, podemos destacar dois elementos importantes: 1) a angústia como afeto aproxima tal pressuposto lacaniano com a teoria freudiana, que também define a angústia como sendo um afeto; 2) a experiência da angústia não permite o engano, o que abre a questão para a suposição de que algo engana. Caberia, nesse caso, especificar qual seria o outro termo deste paradoxo. Lacan afirma que:

Os significantes fazem do mundo uma rede de traços em que a passagem de um ciclo a outro torna-se então possível. Isso quer dizer que o significante gera um mundo, o mundo do sujeito falante, cuja característica essencial é que nele é possível enganar. A angústia é esse corte - esse corte nítido sem o qual a presença do significante, seu funcionamento, seu sulco no real, é impensável; é esse corte a se abrir, e deixando aparecer o que vocês entenderão melhor agora: o inesperado, a visita [...]. (1962-63/2005, pp. 87-88)

O que se tem da ordem do engano não é o significante em si, mas este "mundo" que, a partir do significante, é possível gerar. Os significantes permitem ao sujeito dar forma ao seu mundo, criar sua própria história, sua fantasia fundamental. Nessa fantasia, o sujeito se coloca em posição de objeto a do desejo desse Outro. Lacan afirma que "esse objeto a que o neurótico se leva a ser em sua fantasia cailhe quase tão mal quanto polainas num coelho. É por isso que o neurótico nunca faz grande coisa com sua fantasia" (1962-63/2005, pp. 60-61). Em outras palavras, é por isso que não responde ao "que queres de mim?", pergunta endereçada ao Outro. Por outro lado, retomando a citação do texto lacaniano, a angústia é o "corte a se abrir", ou seja, está no intervalo, ou ainda, nas fendas entre um significante e outro que compõem os encadeamentos significantes estruturantes da posição do sujeito. Quando alguém procura um analista, um dos motivos pode ser porque já não suporta o fracasso do fantasma que construiu para tentar responder ao Che voi? O momento em que surge a angústia teria relação com esta pergunta e, desta maneira, estaria implicada no desejo do Outro. O que interessa à psicanálise é, dentre outras questões, saber para que direção apontam os sinais orgânicos da angústia (taquicardia, sudorese, sensação de sufocamento, etc.) no que tange à verdade do sujeito inconsciente. Assim, em oposição aos sistemas nosográficos modernos, a psicanálise busca respostas nas formas de estruturação do discurso a partir dos significantes do sujeito, e não a partir da descrição dos sinais orgânicos, destacados como critérios diagnósticos nos manuais tais como o DSM e CID-10.

De acordo com a psicanálise, em Freud e Lacan, a linguagem é estruturante da subjetividade e esta se dá a partir de um vazio fundamental. Este vazio se estrutura com a entrada do sujeito no discurso, trata-se de uma operação de corte, de cisão criada pela linguagem, que desnaturaliza o sujeito. Segundo Carvalho (2005), o vazio insiste, sendo um lugar que nada que o sujeito alcance pode preencher. Ainda que passe a vida a buscar significantes que deem sentido à sua existência, o vazio persiste. E, ainda segundo a autora, na análise, uma função da angústia seria apontar para este lugar fundante do sujeito.

Durante o processo analítico, ao se posicionar de acordo com o discurso do analista (Lacan, 1969-70/1992), ou seja, de sua postura de não responder à demanda imediata do paciente, este discurso atua como operação de cisão e os sujeitos se deparam com este vazio, já que não obtém do analista nenhuma resposta que lhe diga o que fazer com suas questões a não ser que fale delas. A angústia, conforme Carvalho (2005), tem como função no processo analítico apontar justamente para o lugar em que o sujeito se fundamenta, para que caiam as construções imaginárias em resposta ao desejo do Outro. Mas esta queda não depende apenas do que responde ou não o psicanalista, requer também que o paciente se implique em termos de responsabilidade diante de seu sofrimento. É necessário que o paciente assuma a parte que lhe cabe em seu sintoma a partir de sua posição de sujeito, pois, caso contrário, não há análise possível. Segundo Lacan (1962-63/2005):

O sintoma só se constitui quando o sujeito se apercebe dele [...]. O primeiro passo da análise [...] é que o sintoma se constitua em sua forma clássica, sem o que não haverá meio de sair dele, porque não haverá meio de falar dele, porque não há como agarrar o sintoma pelas orelhas. $\mathrm{O}$ que é a orelha em questão? É o que podemos chamar de 
o não-assimilado do sintoma, não assimilado pelo sujeito. Para que o sintoma saia do estado de enigma ainda não formulado, o passo a ser dado não é que ele se formule, mas que se desenhe no sujeito uma coisa tal que lhe seja sugerido que há uma causa disso. (p. 306)

Não se trata de dizer que o sintoma não existia antes da análise, mas ele se constitui como tal a partir do momento em que o sujeito assume sua implicação subjetiva com o sintoma, quando nota que não é por acaso, quando deixa de ser uma queixa inicial e passa a ser uma demanda de análise. É frequente serem encaminhadas para análise pessoas que chegam com o diagnóstico de depressão, ansiedade generalizada, transtorno do pânico, estresse, e este último, por exemplo, segundo Izcovich (2011), não se trata de uma posição subjetiva, mas uma resposta exigida pelo social e um modo de não implicar-se como sujeito. Na angústia dar-se-ia o contrário, pois, segundo o autor, o sujeito estaria implicado na própria angústia enquanto responsável por ela. Ele faz um paralelo entre a passagem da queixa ao sintoma e do estresse à angústia, sendo esta última o modo de aceder ao desejo.

Assim como é necessário que o sujeito passe da queixa ao sintoma, deve-se passar do estresse à angústia, cuja implicação do sujeito também se faz fundamental para a entrada em análise. De acordo com Lacan, ainda no seminário sobre a angústia, o neurótico chega ao analista com uma oferta falaciosa; "pois bem, nós a aceitamos. [...] Ele quer que vocês lhe peçam alguma coisa. Como vocês não lhe pedem nada, começa a modular as demandas dele [...]. É essa a primeira entrada em análise" (Lacan, 196263/2005, pp. 62-63). Então, o analista, além de não pedir nada, também não responde à demanda do: "o que eu tenho?", “O que devo fazer?", “O que você me sugere?”. A isto responde com a regra fundamental da psicanálise: fale o que vier à cabeça, sem crítica, seleção ou julgamento. Assim é possível que se dê a entrada em análise.

Lacan (1962-63/2005) afirma que a angústia seria o corte que incide nas fendas entre um significante e outro deixando à vista o inesperado. Com esta afirmação, o autor refere-se ao Unheimliche freudiano, traduzido para o português por “O Estranho" (Freud, 1919/1996). Neste texto, Freud expõe uma série de significados para a palavra heimlich que, em linhas gerais relaciona-se a algo que é familiar, porém, "é uma palavra cujo significado se desenvolve na direção da ambivalência, até que finalmente coincide com o seu oposto unheimlich" (p. 244). Para Lacan, "a definição do unheimlich é ser heimlich" (1962$63 / 2005$, p. 57). Freud propõe que se trata do retorno do recalcado, ou seja, um infantil familiar que se tornou estranho pelo efeito do recalque. Lacan afirma que o heim (estranho-familiar) é, justamente, o objeto a. Este objeto ele chama de uma espécie de "resto" que fica da operação de divisão do sujeito pelo efeito da castração, na qual este sujeito passa a ser barrado/cindido (\$). Afirma ainda que "a manifestação mais flagrante desse objeto a, o sinal de sua intervenção, é a angústia" (Lacan, 1962-63/2005, p. 98). Então, quando diz que a angústia é o corte que incide nas fendas entre um significante e outro deixando à vista o inesperado, é do objeto a que se trata. É esse objeto que surge quando a angústia aponta para o lugar em que o sujeito se fundamenta, possibilitando a queda das construções fantasmáticas em resposta ao desejo do Outro. Se nos voltarmos para a questão clínica no que tange ao manejo da angústia, uma das possibilidades é de que a travessia da angústia seria necessária durante o processo da análise, pois se trataria fundamentalmente de uma experiência de angústia e, segundo Izcovich (2011), alguns analisantes se angustiam mais, outros menos, mas a concepção lacaniana é a de que não se caminha numa análise sem angustiar-se.

Ainda de acordo com Izcovich, há um paradoxo da análise: neste processo o analista vem a ocupar o lugar de objeto a. Ao ocupar este lugar, o analista evoca a angústia e, ao mesmo tempo o desejo do analisando. Segundo Carvalho (2005), a análise questiona o sujeito na raiz do seu desejo, ou seja, no lugar em que está somente como causa de desejo. Além disso, no manejo da transferência, o desejo do analista seria fundamental por sua não-resposta à demanda do paciente, o que pode mobilizar angústia.

Lacan teoriza sobre o discurso do analista e sua posição de objeto a no Seminário 17 , no qual aborda os quatro discursos: da histérica, do mestre, do universitário e do analista (1969-70/1992). Seguindo a lógica dos quatro discursos, ao ocupar o lugar de objeto a, o analista possibilita que o analisante, partindo do reconhecimento de ser sujeito barrado pelo desejo, possa sair da posição imaginária de objeto do Outro para interrogar-se a respeito de sua própria estrutura significante. $\mathrm{O}$ analista faz isso a partir do momento em que, ao esvaziar o semblante, responde apontando para o desejo enquanto causa. Como é possível ao analista ocupar este lugar e agir no manejo da angústia sem que ela inviabilize a continuação da análise? Carvalho (2005) afirma que "isso só é possível porque o analista passou por uma análise e adquiriu a capacidade de suportar sua própria angústia" (pp. 44-45). Não estamos certos de tratar-se somente da capacidade adquirida pelo analista de suportar a própria angústia, mas, sim, de fazer a travessia dela e, a partir disso, conforme Lacan (1962$63 / 2005$ ), sentir o que o sujeito em análise pode suportar da angústia, pois é isto o que nos coloca a prova como analistas. Atravessar a angústia não é o mesmo que adquirir a capacidade de suportá-la, é fazer questionamentos sobre sua posição de sujeito para que um desejo enquanto ato de enunciação possa advir. Desta maneira o analista pode 
apostar que a angústia do paciente é necessária para que o desejo advenha.

Segundo Carvalho (2005), o sujeito, ao vivenciar essa angústia em toda sua intensidade, se torna capaz de assumir uma nova posição em relação a sua estrutura. Pode, então, desejar por si, ao se deparar com o que Freud chamou de desamparo inicial da cria humana (1895/1996a), ou para o que "não há esperança", nos termos de Iscovich (2011), a partir do momento em que se descobre que não há nada para além daquilo que outrora criamos, ou seja, o mito individual neurótico. Segundo Freud, inicialmente o organismo humano, imaturo, seria incapaz de promover uma ação específica de obtenção de prazer e precisaria, desta forma, de auxílio externo. Este desamparo seria a "fonte primordial de todos os motivos morais" (1895/1996a, p. 380). Segundo Rocha (2000), o Hilflosigkeit (desamparo), etimologicamente aponta o estado de incapacidade em que se encontra o sujeito de ajudar-se por si, isto é, com seus próprios recursos. A experiência inicial de desamparo seria vivenciada pelo recém-nascido, mas se repetiria em situações de perigo a posteriori, a cada vez que o sujeito se deparasse com a possibilidade de "falência de sua organização psíquica" (p. 67). Em tais situações, o sujeito seria invadido por uma forte reação de angústia.

Por outro lado, retomando Carvalho (2005), seria a partir desta angústia que o sujeito poderia assumir um novo posicionamento em relação a sua estrutura. Trata-se, pois, de construir um caminho novo que possibilite outro desejo, inédito, que não seja a testemunha de uma dependência fracassada em relação ao Outro. Pois se a máxima lacaniana de não ceder quanto ao desejo é a essência da ética psicanalítica, então, a resposta que poderia dar o analista para a angústia do analisante seria a de fazer o seu discurso coincidir com o do desejo como causa.

\section{Considerações Finais}

Segundo o que foi exposto, não há um estatuto conceitual fechado a respeito do conceito de angústia em psicanálise, já que Freud estabelece duas possibilidades e Lacan, outra, a partir de seu axioma do inconsciente estruturado como uma linguagem. Na primeira teoria freudiana trata-se de um afeto automaticamente transformado em angústia, na segunda, a partir de suas teorizações sobre o eu, a angústia tem como função proteger o eu de ameaças externas e, principalmente, das internas ao aparelho psíquico. Portanto, para Freud, a angústia implica em causalidade, diferentemente dos sistemas nosográficos, que depuram o fenômeno como entidade universal sem relação com o sujeito e suas produções. Em Lacan, a angústia seria também um afeto e surgiria nos intervalos entre um significante e outro. Seu surgimento apontaria para a linguagem enquanto estruturante de um mundo não natural, e o mal-estar sentido no corpo estaria relacionado com os modos de enfrentamento desta falta estrutural do sujeito da linguagem. Assim, sob o ponto de vista psicanalítico, a angústia não existe enquanto fenômeno depurado e independente do sujeito, ao contrário, faz parte de sua constituição subjetiva. Partimos do axioma do inconsciente estruturado como uma linguagem para afirmar que a angústia é também um dos elementos desta constituição enquanto diretamente relacionada com a falta e o mal-estar subjetivo diante disso. Portanto, a angústia é mais um dos elementos da teoria psicanalítica que deve ser descolado de abordagens biologizantes para ser compreendida no campo da linguagem.

\section{Referências}

American Psychiatric Association [APA]. (2002). Manual diagnóstico e estatístico de transtornos mentais DSM$I V-T R$. Porto Alegre: Artes Médicas.

André, J. (2001). Entre angústia e desamparo. Ágora: Estudos em Teoria Psicanalítica, 4(2), 95-109.

Beividas, W., \& Ravanello, T. (2009). Linguagem como alternativa ao aspecto quantitativo em psicanálise. Psicologia \& Sociedade, 21(spe), 82-88.

Campos, É. B. V. (2004). A primeira concepção freudiana de angústia: Uma revisão crítica. Ágora: Estudos em Teoria Psicanalítica, 7(1), 87-107.

Carvalho, M. C. D. (2005). A função da angústia na análise. Stylus, 10, 42-48.

Castilho, P. T. (2007). Uma discussão sobre a angústia em Jacques Lacan: Um contraponto com Freud. Revista do Departamento de Psicologia, 19(2), 325-337.

Ceccarelli, P. R. (2009). Laço social: Uma ilusão frente ao desamparo. Revista Reverso, 31(58), 33 - 42.

Costa, V. A. S. F, \& Queiroz, E. F. (2011). Transtorno de pânico: Uma manifestação clínica do desamparo. Psicologia: Ciência e Profissão, 31(3), 444-456.

Dunker, C.I.L. (2006). A angústia e as paixões da alma. In N. V. A Leite (Org.), Corpolinguagem - Angústia: o afeto que não engana (pp. 305-316). Campinas, SP: Mercado de Letras.

Dunker, C.I.L., \& Kyrillos Neto, F. (2011). A crítica psicanalítica do DSM-IV: Breve história do casamento psicopatológico entre psicanálise e psiquiatria. Revista Latinoamericana de Psicopatologia Fundamental, 14(4), 611-626.

Freud, S. (2003). A Interpretação das Afasias. Lisboa: 
Edições 70. (Originalmente publicado em 1891)

Freud, S. (1996). Algumas considerações para um estudo comparativo das paralisias motoras orgânicas e histéricas. In J. Strachey (Ed.), Edição Standard Brasileira das Obras Psicológicas Completas de Sigmund Freud (Vol.1). Rio de Janeiro: Imago. (Originalmente publicado em 1893)

Freud, S. (1996). Rascunho E: Como se origina a Angústia? In J. Strachey (Ed.), Edição Standard Brasileira das Obras Psicológicas Completas de Sigmund Freud (Vol. 1) Rio de Janeiro: Imago. (Originalmente publicado em 1894)

Freud, S. (1996b). Sobre os Fundamentos para Destacar da Neurastenia um Síndrome Específica Denominada "Neurose de Angústia". In J. Strachey (Ed.), Edição Standard Brasileira das Obras Psicológicas Completas de Sigmund Freud (Vol. 3). Rio de Janeiro: Imago. (Originalmente publicado em 1895)

Freud, S. (1996). A interpretação dos sonhos. In J. Strachey (Ed.), Edição Standard Brasileira das Obras Psicológicas Completas de Sigmund Freud (Vol. 4 e 5). Rio de Janeiro: Imago. (Originalmente publicado em 1900)

Freud, S. (1996) Os instintos e suas vicissitudes. In J. Strachey (Ed.), Edição Standard Brasileira das Obras Psicológicas Completas de Sigmund Freud (Vol. 14). Rio de Janeiro: Imago. (Originalmente publicado em 1914)

Freud, S. (1996). O Recalque. In J. Strachey (Ed.), Edição Standard Brasileira das Obras Psicológicas Completas de Sigmund Freud (Vol. 14). Rio de Janeiro: Imago. (Originalmente publicado em 1915)

Freud, S. (1996). Conferência XXV: A Angústia. In J. Strachey (Ed.), Edição Standard Brasileira das Obras Psicológicas Completas de Sigmund Freud (Vol. 16). Rio de Janeiro: Imago. (Originalmente publicado em 1917)

Freud, S. (1996). O Estranho. In J. Strachey (Ed.), Edição Standard Brasileira das Obras Psicológicas Completas de Sigmund Freud (Vol. 17). Rio de Janeiro: Imago. (Originalmente publicado em 1919)

Freud, S. (1996). Inibições, Sintomas e Angústia. In J. Strachey (Ed.), Edição Standard Brasileira das Obras Psicológicas Completas de Sigmund Freud (Vol. 20). Rio de Janeiro: Imago. (Originalmente publicado em 1926)

Green, A. (1982). O discurso vivo: Uma teoria psicanalítica do afeto. Rio de Janeiro: Editora Francisco Alves.
Imbasciati, A. (1998). Afeto e representação. São Paulo: Ed. 34.

Izcovich, L. (2011). Los afectos en la experiencia analítica. Medellín: UPB.

Lacan, J. (1998). Função e campo da fala e da linguagem. In J. Lacan, Escritos. Rio de Janeiro: Zahar.

Lacan, J. (2005). O Seminário livro 10, A angústia (196263). Rio de Janeiro: Zahar.

Lacan, J. (1992). O Seminário livro 17, O avesso da psicanálise (1969-70). Rio de Janeiro: Zahar.

Lacan, J. (2003). Televisão. In J. Lacan, Outros Escritos. Rio de Janeiro: Zahar.

Lacan, J. (1985). Conferência em Genebra sobre o Sintoma. Le Bloc-Notes de la psychanalyse, 5, 5-23.

Leite, S. (2011). Angústia. Rio de Janeiro: Jorge Zahar Ed.

Lourenço, L. C. d'A. (2009). A pulsão de morte e a gênese da angústia. Ágora: Estudos em Teoria Psicanalítica, 12(1), 101-117.

Lyra, C. E. de S. (2008). Afetos, representações e psicopatologias: Da angústia ao pânico. Psicologia Clínica, 20(1), 219.

Maurano, D. (2010). Histeria: O princípio de tudo. Rio de Janeiro: Civilização Brasileira.

Pisetta, M. A. A. M. (2008). Considerações sobre as teorias da angústia em Freud. Psicologia: Ciência e Profissão, 28(2), 404-417.

Quinet, A. (2009). Com la língua no corpo. Stylus, 19, 6975.

Ravanello, T. (2009). Elementos para uma abordagem discursiva do afeto: Estudo de interface entre psicanálise e semiótica tensiva. Rio de Janeiro: UFRJ/ PPGTP.

Rocha, Z. (2000). Os destinos da angústia na psicanálise freudiana. São Paulo: Escuta.

Vieira, M. A. (2001). A ética da paixão: Uma teoria psicanalítica do afeto. Rio de Janeiro: Jorge Zahar.

Viola, D. T. D., \& Vorcaro, Â. M. R. (2011). A verdade e o engodo do desejo na leitura do seminário a angústia de Jacques Lacan. Ágora: Estudos em Teoria Psicanalítica, 14(1), 77-93.

World Health Organization [WHO]. (1993). Classificação de transtornos mentais e de comportamento da CID10: Descrições clínicas e diretrizes diagnósticas. Porto Alegre: Artmed. 


\section{Endereço para Correspondêcia:}

Isloany Dias Machado

Endereço: Rua Francisco Amaral Militão, nº 698, Jardim

das Perdizes. Campo Grande/MS - CEP 79063-180

E-mail: isloanymachado@gmail.com

\section{Endereço para Correspondêcia:}

Tiago Ravanello

Universidade Federal de Mato Grosso do Sul, Centro de Ciências Humanas e Sociais, Graduação em Psicologia e

Programa Pós-Graduação em Psicologia/Mestrado.

Cidade Universitária, s/n, Sala 8, CCHS. CEP 79070-900 -

Campo Grande/MS - Brasil - Caixa-postal: 549.

E-mail: tiagoravanello@yahoo.com.br 